\title{
Obstetric profile of perinatal deaths on a capital of the Northeast of Brazil
}

Maria Alice de Moraes Machado Brito 1

https://orcid.org/0000-0002-2046-8909

Marina Barguil Macêdo 2

D https://orcid.org/0000-0002-8927-5566

Janaína de Moraes Machado Brito 3

D.tps://orcid.org/0000-0002-7493-1049

Luísa Helena de Oliveira Lima 4

https://orcid.org/0000-0002-1890-859X

Catarina Fernandes Pires 5

https://orcid.org/0000-0001-8579-4628

Plínio da Silva Macêdo 6

https://orcid.org/0000-0002-3801-1800

Viriato Campelo 7

https://orcid.org/0000-0002-7515-2389

1,5 Departamento Materno-Infantil. Universidade Federal do Piauí. Teresina, PI, Brasil.

2 Departamento de Imunologia. Instituto de Ciências Biomédicas. Universidade de São Paulo. Av. Prof. Lineu Prestes, 1730. Butantã. São Paulo, SP, Brasil. CEP: 05.508-900. E-mail: marina.macedo@fm.usp.br

3 Faculdade Integral Diferencial. Teresina, PI, Brasil

4 Universidade Federal do Piauí. Campus Senador Helvídio Nunes de Barros. Picos, Pl, Brasil.

6 Departamento de Patologia e Clínica Odontológica. Universidade Federal do Piauí. Teresina, PI, Brasil

7 Departamento de Parasitologia e Microbiologia. Universidade Federal do Piauí. Teresina, PI, Brasil

\section{Abstract}

Objectives: to analyze the obstetric and sociodemographic profile on perinatal deaths in Teresina the capital of Piaui, from data obtained from the Sistema de Informação de Mortalidade e Sistema de Informação de Nascidos Vivos (Brazilian Mortality Information System and Livebirth Information System).

Methods: this is a retrospective cohort on perinatal deaths of mothers whose babies were born and resided in Teresina between 2010 and 2014. The analyzed variables were age and the mother's schooling, gestational age, type of pregnancy (singleton or multiple), route of delivery (vaginal or cesarean), place of death (in and out hospital), time of death in relation to the delivery (prior, during or after), and birth weight.

Results: the perinatal mortality coefficient (PMC) varied from 17.5 to 19.3 per 1,000 births. We found similarities in the sociodemographic profile and in the obstetric fetal and non-fetal deaths, both with a great incidence on 20 to 27 years-old mothers, vaginal delivery and singleton pregnancy. Low birth weight was positively related to early neonatal deaths.

Conclusions: perinatal mortality presented a statistical correlation in gestational age, birth weight, and type of delivery. The PMC in our study was higher than other Brazilian capitals.

Key words Perinatal mortality, Perinatal care, Health status indicators, Quality indicators in healthcare, Pregnancy 


\section{Introduction}

Perinatal mortality is conceptually defined as the sum of fetal and neonatal deaths. ${ }^{1}$ Its first component, the fetal mortality rate (FMR), is the ratio between the deaths of fetuses with more than 22 weeks of gestational age (stillbirths) and the number of births in a given locality, on a specified time interval. Early neonatal mortality rate (ENMR), by its turn, is the number of deaths of neonates up until seven days after birth divided by the number of live births in a given locality, on a specified time interval. Abiding by standardization, this ratio is expressed per 1,000 live births (LB), and the temporal frame usually employed is of a year.2,3

Thus, the perinatal mortality rate (PMR) is the sum of deaths occurring from the 22 nd week of gestation to the 7 th day of extrauterine life. This coefficient is a relevant parameter for evaluating the quality of public health in a country, and, more specifically, the quality of assistance provided to both pregnant women and infants, reflecting further the socioeconomic context to which mother and child pertain. 4

In order to diminish Brazilian maternal and neonatal mortality, federal programs to improve the quality of assistance of expecting mothers and neonates have gained force on the last decades. In 2004, the "Pact for Reduction of Maternal and Neonatal Mortality" was established with this intent. 5

Deficient prenatal care became one of the main factors to be focused on the struggle against perinatal mortality. A better structured prenatal followup could curb a great percentage of deaths, and from this stems the concept of potentially avoidable deaths. Brazilian Ministry of Health issued, in 2011, directives to consolidate access and continuity of prenatal, parturition and postpartum care, encompassed by the health policy denominated as "Stork Network". This network could intervene on lacking aspects of care based on the collecting and processing of updated sociodemographic data about the causes of perinatal mortality in each region of the country. 6,7

Paralleling the Stork Network principles, and considering the scarcity of studies about perinatal mortality in our region, we aimed to evaluate maternal and neonatal assistance in Teresina, capital of Piauí, through the characterization of factors that could contribute and impact on PMR, by analyzing the records from the country's two largest registry databases: the Mortality Information System (SIM) and the Live Births Information System (SINASC).

This study preserved confidentiality and anonymity of the analyzed subjects, in accordance to National Health Council resolution 466/12, having been registered on Brazil Platform, a platform to judge conformity to ethics in research studies involving living beings, monitored by the National System of Ethics in Research (SISNEP). It has been approved by the Ethics Committee of the Federal University of Piauí, certificated by the number CAAE 43159815.4.0000.5214.

\section{Methods}

This is a retrospective observational cohort comprised of fetal and early neonatal deaths occurred in Teresina, Piauí, from January 1st, 2010, to December 31st, 2014. Data was collected from SIM and SINASC electronic databases, between September and December 2015.

A form for data gathering was applied, in which the following variables were checked and filled for each included death: maternal age, maternal education level, type of pregnancy (singleton versus multiple), mode of delivery (vaginal versus cesarean), place of death (inside versus outside hospital), time of death in regards to delivery (antepartum versus during parturition versus postpartum, for fetal deaths; on the 1 st hour of life versus between the 1st and 24th hour of life versus between the $1^{\text {st }}$ and $6^{\text {th }}$ day of life, for neonatal deaths), gestational age, and birth weight.

Inclusion criteria were, for fetal deaths, demise being recorded on SIM, and, for neonatal deaths, both birth being recorded on SINASC and demise being recorded on SIM. Exclusion criteria were absence of information on the registry about mode of delivery or gestational age.

Data was assembled on the software SPSS for Windows version 20.0. Graphs were constructed with the aid of GraphPad Prism version 5.01. We used descriptive statistics for univariate analysis. Double-entry tables and Chi-Square Test were used for bivariate analysis. Relative risk was calculated with a confidence interval of $95 \%$. A significance level of 0.05 was adopted for all tests. 


\section{Results}

Between January 1st, 2010 and December 31st, 2014, a total of 1,250 perinatal deaths were registered in Teresina, from which 686 were of fetuses with more than 22 weeks of age, and 564 of infants up to 7 days of age. PMR fluctuated between 17.5 and 19.3 per 1,000 births, with a tendency of decreasing on the period, stabilizing in 17.6 in 2014 (Figure 1A).

We found a statistical significant association between fetal deaths and both maternal age and maternal education level. The majority of fetal deaths happened in women of 20 to 33 years-old $(p=0.003)$ : in 2010 , this age range concentrated $46.67 \%$ of deaths; in 2011, 57.14\%; in 2012, $54.29 \%$; in $2013,51.83 \%$; and in $2014,60.19 \%$ (Figure 1B).

The peak incidence of fetal deaths was identified in mothers who had 8 to 11 years of study $(p=0.015)$ : in 2010 , it corresponded to $25.33 \%$; in 2011 , to $28.75 \%$; in 2012 , to $27.86 \%$; in 2013 , to $36.50 \%$; and in 2014 , to $46.62 \%$. It is noteworthy that a high percentage of registries had this variable missing, and, by the passing of the years, more complete registries were retrieved - while in 2010 the maternal education level was unavailable on $53 \%$ of registries, in 2014, blank registries amounted to only 18\% (Figure 1C).

Gestational age in which most fetal deaths occurred was between 32 and 36 weeks, from 2011 to $2014(29.37 \%, 36.43 \%, 35.77 \%$, and $28.57 \%$, respectively), with the year of 2010 being an exception, since fetal deaths on that particular year predominated on 22 to 27 weeks of gestational age $(30.0 \%)$. In neither case, however, statistical significance was reached $(p=0.09)$.

Singleton pregnancies prevailed on registries (91.3\% in $2010,96.03 \%$ in $2011,96.43 \%$ in 2012 , $93.43 \%$ in 2013 , and $95.49 \%$ in 2014 ), but an excess of fetal deaths could not be attributed to type of pregnancy $(p=0.21)$. The most frequent mode of delivery was vaginal $(70.67 \%$ in $2010,61.90 \%$ in $2011,67.86 \%$ in $2012,67.15 \%$ in 2013 , and $60.15 \%$ in 2014), but that also was not significant ( $p=0.14$ ).

Death was witnessed mostly in hospitals: $94 \%$ in $2010,100 \%$ in $2011,99.29 \%$ in $2012,97.81 \%$ in 2013 , and $93.98 \%$ in 2014. Antepartum was the most frequent moment of death: $100 \%$ in $2010,96.03 \%$ in $2011,99.29 \%$ in $2012,97.08 \%$ in 2013 , and $96.99 \%$ in 2014.

Concerning early neonatal deaths on the five- year period analyzed, $16.31 \%$ were verified on the first hour of life, $38.83 \%$ between the first and $24^{\text {th }}$ hour of life, and $44.86 \%$ between the first and sixth day of life.

The majority of mothers of the deceased infants was between 20 and 27 years-old and had a singleton pregnancy. On the period, only 32 deaths from twin pregnancies and 6 deaths from triplets pregnancies were registered, while singleton pregnancies accounted for 500 deaths. The number of fetus per gestation was not registered in 26 deaths.

Fifteen point six percent of singletons died on their $1^{\text {st }}$ hour of life, $38.6 \%$ between their $1^{\text {st }}$ and $24^{\text {th }}$ hour of life, and $45.8 \%$ between their $1^{\text {st }}$ and $6^{\text {th }}$ day of life. Twenty one point eighty eight percent of twins died on their 1 st hour of life, $37.5 \%$ between their 1 st and 24 th hour of life, and $40.63 \%$ between their 1 st and $6^{\text {th }}$ day of life. Fifty percent of triplets died on their 1 st hour of life, $33.33 \%$ between their 1 st and 24 th hour of life, and $16.67 \%$ between their 1 st and 6th day of life.

We found no correlation between time at death with either maternal age $(p=0.887)$ or pregnancy type $(p=0.182)$. On the other hand, time at death correlated positively with mode of delivery ( $p=0.001$ ): $68.18 \%$ of the deaths on the first hour of life were born by vaginal delivery, while $52.08 \%$ of the deaths between the first and sixth day of life were delivered by c-section (Figures 2A and 2D).

Gestational age also correlated with time of death. Most neonates who died on the first day of life were between 22 and 27 weeks of gestational age (35.9\% of those who died on the first hour of life, and $31.02 \%$ of those who died between the first and twenty-fourth hour of life). By its turn, the majority of deaths $(28.75 \%)$ that happened between the first and sixth day of life was of neonates between 28 and 31 weeks of gestational age (Figures 2B and 2D).

We also found a positive correlation between early neonatal deaths and extremely low birth weight (41.13\% of deaths, $p<0.001)$. Of those, $41.8 \%$ died between the $1^{\text {st }}$ and $24^{\text {th }}$ hour of life. Neonates whose birth weight was other than extremely low birth weight (ELBW) died mostly between the $1^{\text {st }}$ and $6^{\text {th }}$ day of life, comparatively (Figures 2C and 2D).

Thus, on our population, identified risk factors for early neonatal deaths were vaginal delivery (relative risk - RR of 1.86 , confidence interval - CI 1.49 to 2.23 ), gestational age between 22 and 27 weeks (RR 102.25, CI 61.36 to 143.14), and ELBW (RR 92.48 , CI 77.47 to 107.49 , as shown in Table 1). 
Figure 1

Maternal profile on fetal mortality in Teresina, Piauí, Brazil, from 2010 to 2014.
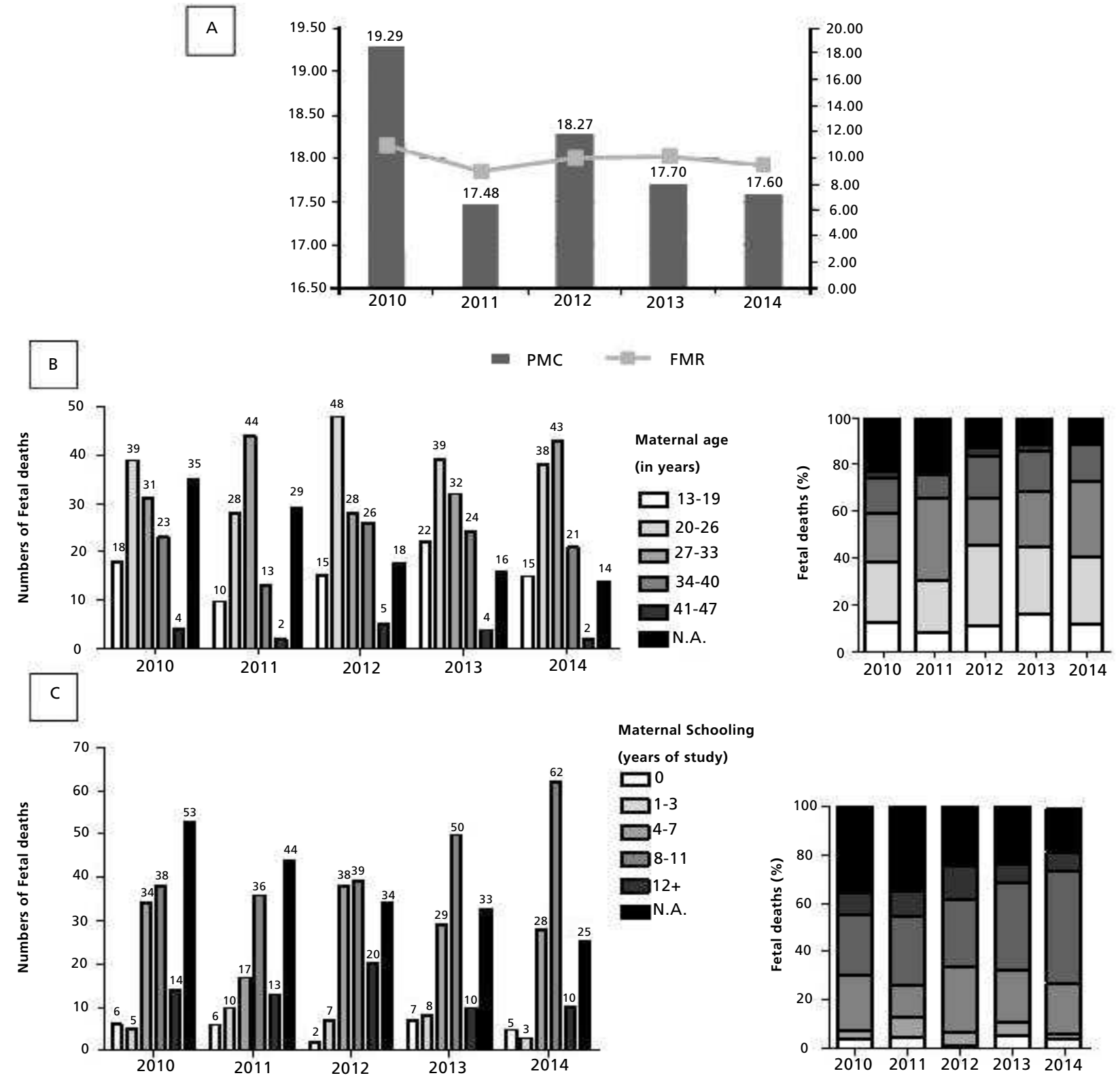

Source: Sistema de Informação de Mortalidade, (Mortality Information System) 2015. Subtitles: In (A) the bars represent Perinatal Mortality Coefficient (PMC, Y axis to the left) and the line represents Fetal Mortality Coefficient (FMC, Y axis to the right). In (B) distribution of fetal deaths according to maternal age, with absolute values per year on the left graphic and percentage numbers per year on the right graphic. In (C) distribution of fetal deaths according to maternal schooling, with absolute values per year on the left graphic, with percentage numbers per year on the right graphic. 

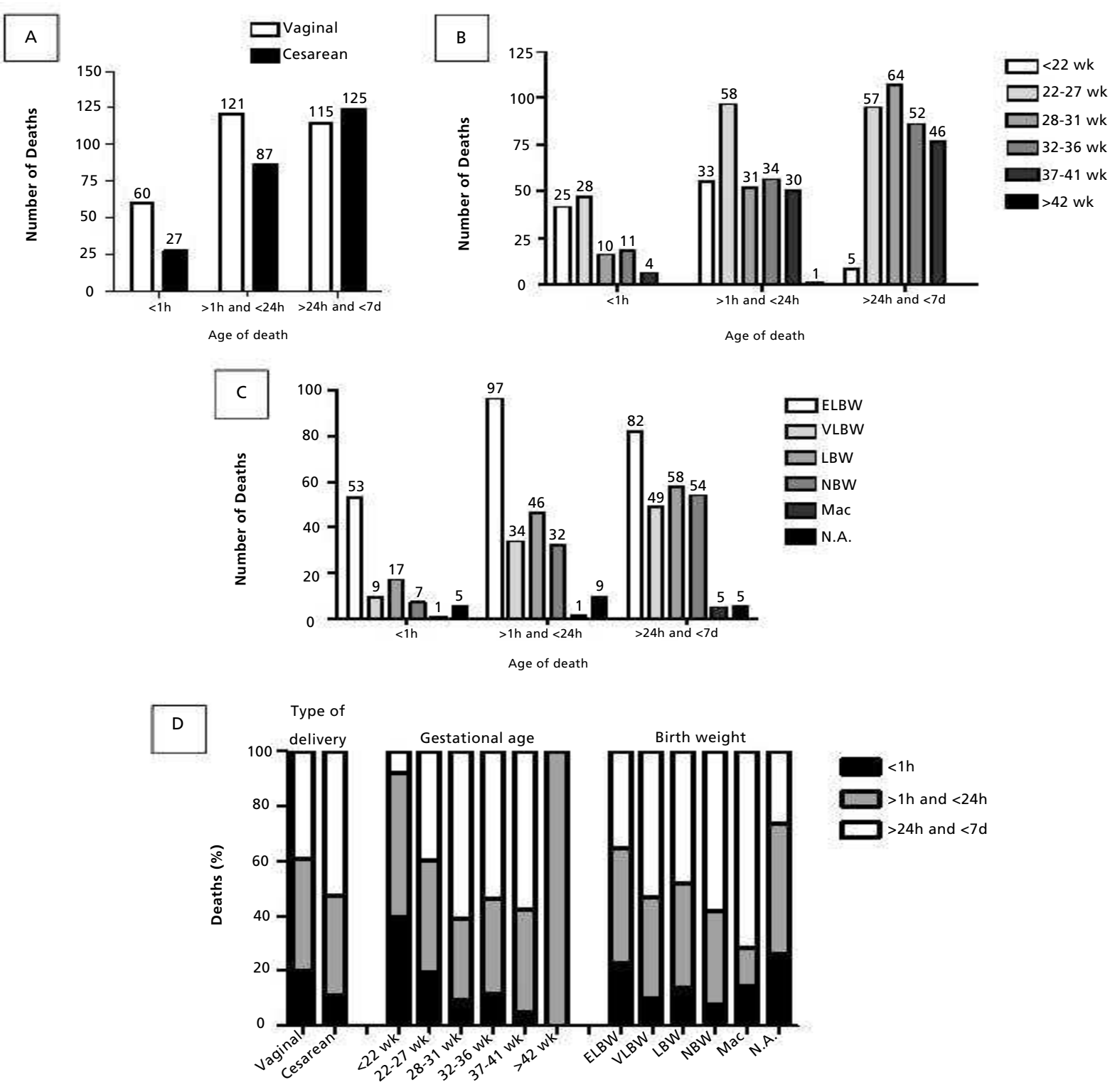

Source: Sistema de Informação de Mortalidade, (Mortality Information System). 2015. Subtitles: Distribution of early neonatal deaths, in absolute values, according to age of death and type of delivery (A), gestational age (B), and birth weight (C). In (D). Distribution of early neonatal deaths em terms of percentage, according to the variables already mentioned. $h$ - hour, $d$ - day, wk - week, ELBW - extremely low birth weight, VLBW - very low birth weight, LBP - low birth weight, NBW - normal birth weight, Mac - macrosomic, N.A. - data not available. 
Relative risk for early neonatal death in relation to type of delivery, gestational age and birth weight, in Teresina, Piauí, Brasil, from 2010 to 2014.

\begin{tabular}{|c|c|c|c|c|c|}
\hline \multirow[t]{2}{*}{ Obstetric Variable } & \multicolumn{3}{|c|}{ Death $<7$ th day } & \multirow[t]{2}{*}{ RR } & \multirow[t]{2}{*}{$\mathrm{Cl} 95 \%$} \\
\hline & Yes & No & Total & & \\
\hline \multicolumn{6}{|l|}{ Type of delivery } \\
\hline Vaginal & 296 & 26977 & 27273 & & \\
\hline Cesarean & 239 & 40731 & 40970 & 1.86 & $1.49-2.23$ \\
\hline Total & 535 & 67708 & 68243 & & \\
\hline \multicolumn{6}{|c|}{ Gestational age (weeks) } \\
\hline $22-27$ & 143 & 178 & 321 & & \\
\hline$>27$ & 283 & 64674 & 64957 & 102.25 & $61.36-143.14$ \\
\hline Total & 426 & 64852 & 65278 & & \\
\hline \multicolumn{6}{|c|}{ Birth weight (grams) } \\
\hline$<1000$ & 235 & 322 & 557 & & \\
\hline$>1000$ & 310 & 67641 & 67951 & 92.48 & $77.47-107.49$ \\
\hline Total & 545 & 67963 & 68508 & & \\
\hline
\end{tabular}

$\mathrm{RR}=$ Relative risk; $\mathrm{Cl}=$ Confidence Interval; In the period of this study, a total of 68,508 live births and 564 early neonatal deaths (until seven days of life) were registered. The total number for each variable studied may be less of the total number of registries due to the exclusion in which the analyzed information was missing or incomplete.

\section{Discussion}

A meaningful percentage of neonates die of avoidable or potentially treatable disease. World Health Organization (WHO) estimates that, annually, about four million infants die on the neonatal period, with the greatest risk of death on the first twenty-four hours of life. 8

From 1990 to 2011 , mortality of infants between the first and fifty-ninth months of life decreased $47 \%$ worldwide, and an on-going reduction of $2.9 \%$ per year is expected. Neonatal mortality, in comparison, declines more slowly: on this same period, it decreased about $32 \%$, from 32 per 1,000 LB in 1990, to 22 per 1,000 LB in 2011, i.e., an annual decline of approximately $1.8 \%$. In developing countries, mortality is around 3.7 per $1,000 \mathrm{LB}$, but this rate is up to ten times higher in some countries from Africa and South Asia.4,9

Currently, an average of 7.6 million perinatal deaths is registered yearly, from which $98 \%$ on developing countries. Fetal deaths are responsible for $57 \%$ of this share, and its reduction is even slower than that of early neonatal deaths. Nonetheless, a steady decline is observed worldwide and, on developed countries, mortality decreases on all age ranges. 10

In 2005, on the United States, FMR was of 6.2 per 1,000 LB, similar to infant mortality rate (IMR), which was of 6.9 per 1,000 LB. In contrast, on
Brazil, current IMR corresponds to those verified on developed countries back in the $60 \mathrm{~s}$, and perinatal causes are the main contributor to the high rates of death on the first year of life.4,11

On the last decade, federal policies were established, in our country, envisioning reduction of impoverishment, and enlargement of coverage of public health services, centering on the so-called Family Health Strategy. Associated to continued incentive of exclusive breastfeeding, those measures impacted positively on IMR, reducing death rate from 47.1 per $1,000 \mathrm{LB}$ in 1990 to 15.6 per $1,000 \mathrm{LB}$ in $2010 .^{2}$

Following this pattern, Brazilian Northeast presented an important reduction of $5.5 \%$ on IMR between 1990 and 2007. North and Northeast regions maintain, though, high levels of child mortality, with a rate of 27.2 per $1,000 \mathrm{LB}$, which is $2.1 \mathrm{x}$ higher than that of the South region, and $1.4 \mathrm{x}$ higher than that of Brazil as a whole. In Piauí, IMR decreased from 36.5 per $1,000 \mathrm{LB}$, in 2000 , to 30.4 per $1,000 \mathrm{LB}$, occupying the $18^{\text {th }}$ position on Brazilian infant mortality ranking, and being the state with the lowest IMR on Northeast region. 12

In Teresina, the capital, a study about factors associated with demise in the neonatal period found that, from a total of 231 neonates that required admittance, after birth, on an Intensive Care Unit, between July and December of 2007, 72 died on the neonatal period. Those who died were in their 
majority male $(58.7 \%)$, born by instrumental delivery $(62.2 \%)$, preterm $(90.3 \%$ were less than 37 weeks of gestational age, with the mean gestational age being of 31 weeks), and had a birth weight of less than $2,500 \mathrm{~g}(90.5 \%$ of cases, from which $64.1 \%$ were ELBW, with a mean birth weight of $1,391 \mathrm{~g}$ ). Three quarters of deaths happened on the first seven days of life, and one third in the first twenty-four hours. 13

The highest PMR per year, on the interval of our study, was in 2010, of 19.3 per 1,000 LB. Confronting our rate with that of another capital from Brazilian Northeast, Salvador, in 2009, a high PMR of 20.0 per $1,000 \mathrm{LB}$ is also found, according to Jacinto et al. ${ }^{14}$ study. Nevertheless, decreasing PMR was observed subsequently: in 2011, PMR in Teresina fell expressively, with a slight increase again in 2012, and, between 2013 and 2014, it stabilized around 17.6 per 1,000 LB.

Even so, in Brazilian capitals with a better Human Development Index, as is the case of Curitiba and São Paulo, a much lower PMR is reported, of 12.9 per 1,000 LB and 12.3 per 1,000 LB, respectively.16 And while there was only a tendency of reduction on PMR in Teresina, other Brazilian cities had a significant and profound decrease of their rates around the same period: in Montes Claros, a city of Minas Gerais, PMR diminished from 22.3 per $1,000 \mathrm{LB}$, in 1999 , to 10.5 per $1,000 \mathrm{LB}$, in 2011.17

It is known that maternal age is a relevant variable when considering risk of fetal demise, since both underage and older than 35 years-old mothers constitute a particular risk group. Fetal mortality reaches a nadir on mothers who are 20 to 35 yearsold, and mothers on either extreme of age are require specialized antenatal care. ${ }^{16}$ In our study, however, most fetal deaths occurred from mothers who were between 20 and 33 years-old, which is traditionally viewed as low risk. This could be explained by the fact that births were also more common on this age range. 14

Maternal education level serves as a strong surrogate marker of cultural, behavioral and socioeconomic profile of a family, correlating positively with healthcare attendance. ${ }^{18}$ Our study once again goes against a constructed concept, since most fetal deaths were from mothers who had between 8 to 11 years of study. This could perhaps be attributed to social desirability bias, in which mothers with lower school level deliberately omit this information when questioned, thus contributing to the expressive proportion of unavailable data on such variable on the reviewed forms.
In relation with gestational age, most fetal deaths happened between 32 and 36 weeks, compatible with what is observed in other developing countries. 16 Death of infants with near-normal age and birth weight reflects quality, or lack thereof, of prenatal care. 19 Our data is also comparable to that of previous studies in other Brazilian cities, such as the one of Martins et al. ${ }^{20}$, that demonstrated a prevalence of fetal deaths on gestational age superior to 28 weeks, on the period of 1985 to 2003, in Belo Horizonte, capital of Minas Gerais.

On regards to pregnancy type, our study revealed that most deaths were from singleton gestations, but no conclusive correlation could be taken from this, since singletons greatly outnumbered multiple pregnancies in our population. There was a propensity for singletons dying at a later moment, while twins and triplets died on the first hours after birth.

Death had place mainly inside a hospital, with a non-expressive quantity of deaths being reported in other health care facilities or at home. Most fetal deaths were antepartum, corroborating the findings of other studies that point to inappropriate prenatal care as a factor of major relevance to greater anteand intrapartum mortality. 21

Vaginal delivery was performed in $40 \%$ of pregnancies that evolved with fetal loss, representing the most frequent mode of delivery. Such could be explained by reverse causality, since it is well established that, save for a few exceptions, dead fetuses should preferentially be expelled by vaginal delivery. 22

WHO states that surgical deliveries should not surpass $15 \%$. In our study, however, we found a prevalence four times higher than the recommended, which could suggest that physicians tend to adopt a more aggressive posture when managing a pregnancy with an expected reserved fetal outcome. 23

\section{Final considerations}

We performed a comprehensive study of the main variables related to fetal and early neonatal deaths in Teresina, Piauí, Brazil. Internal validity in our research is strengthened by its inclusive sampling, since all perinatal deaths registered on the national database (SIM) in the designated five-year interval were included for analysis.

By opting to extract and process information consolidated in a unified database, instead of restricting data collection only from maternity hospitals, we could theoretically reduce the risk of selection bias, given that SIM incorporate death records from all healthcare facilities, and even those that 
happened outside a hospital setting. And despite excluding incomplete registries for relative risk calculation, our sample remained representative of our population: for the variables mode of delivery and birth weight, exclusion due to unavailable data led to a loss of only $5.14 \%$ and $3.37 \%$ records, respectively.

PMR characterization showcases major faults at mother and infant care on a given population, permitting inferences about the social, economic and demographic profile of such population, and which aspects on that profile demands intervention. As such, external validity on the sense of extending our findings to other localities is intrinsically impracticable, and even more so when we consider that broad and updated studies in other Brazilian cities are lacking, impairing comparison.

The main limitation of our study arises from the quality of the data gathered from our national databases, SIM and SINASC, that relies on proper filling of Death Declaration form and Live Birth Declaration form. We noticed that, despite information about the fetus/infant being appropriately recorded, information about the mother, as age and education level, was missing in a considerable number of records.

We emphasize the importance of adequately filling official forms, since, beyond their legal role, they are a meaningful source for identifying mortality risk factors and allowing implementation of health promotion policies centered on the quality of prenatal, delivery and child care. Our study reinforces the relevance of data about mortality as a significant tool for directing decisions on health management improvement.

\section{Acknowledgements}

We would like to thank Professor João Batista Telles for his guidance in statistics.

\section{Authors' contributions}

Brito MAMM - data collection, tabulation and interpretation. MB Macêdo - preparation of the graphical elements of the manuscript, statistical analysis and translation of the article into English. Brito JMM elaboration of the introduction. Lima LHO compared the data of the present study with those of other publications, contributed in the writing of the discussion. Pires CF - suggested and included relevant references to the discussion. Macêdo PS and Campelo V - coordination of the study and finalization of the manuscript. All authors approved the final version of the manuscript.

\section{References}

1. WHO (World Health Organization). Neonatal and perinatal mortality: country, regional and global estimates. Geneve; 2006.

2. Brasil. Ministério da Saúde. Manual de vigilância do óbito infantil e fetal e do Comitê de Prevenção do Óbito Infantil e Fetal. Brasília, DF; 2009.

3. Barfield WD. Standard terminology for fetal, infant, and perinatal deaths. Pediatrics. 2016; 137(5): e1-e5.

4. Blencowe H, Cousens S. Addressing the challenge of neonatal mortality. Trop Med Int Health. 2013; 18 (3): 30312 .

5. Brasil. Ministério da Saúde. Síntese de evidências para políticas de saúde: mortalidade perinatal. Brasília, DF; 2012.

6. Santos HG, Andrade SF, Silva AMR, Mathias TAF, Ferrari LL, Mesas AE. Mortes infantis evitáveis por intervenções do Sistema Único de Saúde: comparação de duas coortes de nascimentos. Ciênc Saúde Coletiva. 2014; 19 (3): 907-16.

7. Brasil. Ministério da Saúde. Caderno Humanizasus Humanização do Parto e do Nascimento. Brasília, DF; 2014.

8. Rocha R, Oliveira C, Silva DKFD, Bonfim C. Mortalidade neonatal e evitabilidade: uma análise do perfil epidemiológico. Rev Enferm UERJ. 2011; 19 (1): 114-120.
9. United Nations Children's Fund. Situação Mundial da Infância 2012. New York: UNICEF; 2012.

10. Fonseca SC, Coutinho ESF. Pesquisa sobre mortalidade perinatal no Brasil: revisão da metodologia e dos resultados. Cad Saúde Pública. 2004; 20 (Suppl. 1): S7-S19.

11. Lansky S, França E, Leal MC. Mortalidade perinatal e evitabilidade: revisão da literatura. Rev Saúde Pública. 2002; 36 (6): 759-72.

12. IBGE (Instituto Brasileiro de Geografia e Estatística). Observações sobre a evolução da mortalidade no Brasil: o passado, o presente e perspectivas. Rio de Janeiro; 2010.

13. Silva CMCD, Gomes KR, Rocha OAMS, Almeida IMLMD, Moita Neto JM. Validity and reliability of data and avoidability of the underlying cause of neonatal deaths in the intensive care unit of the North-Northeast Perinatal Care Network. Cad Saúde Pública. 2013; 29 (3): 547-56.

14. Jacinto E, Aquino EML, Mota ELA. Mortalidade perinatal no município de Salvador, Bahia: evolução de 2000 a 2009. Rev Saúde Pública. 2013; 47 (5): 846-53.

15. Sobieray NLEC, Urbanetz AA, Tristão EG. Estudo da mortalidade perinatal do município de Curitiba no período de 2002 a 2005. Arq Med Hosp Fac Cienc Med Santa Casa São Paulo. 2015; 60: 47-53. 
16. Camargo ABMA. Natimortalidade e a mortalidade perinatal em São Paulo. São Paulo Persp. 2008; 22 (1): 30-47.

17. Oliveira E, Souto MB, Santos RO, Fonseca RL, Matos FV, Caldeira AP. Mortalidade Infantil Evitável em Montes Claros, Minas Gerais, Brasil, 1999-2011. Rev Baiana Saúde Pública. 2015; 39 (2): 397-407.

18. Costa GJ. Mortalidade perinatal, determinantes biológicos, de atenção à saúde materno infantil e socioeconômicos: uma análise das desigualdades entre os bairros do Recife [tese]. Recife (PE): Centro de Pesquisas Aggeu Magalhães da Fundação Oswaldo Cruz; 2008.

19. Martins EF, Rezende EM, Lana FCF, Souza KV. Óbitos perinatais investigados e falhas na assistência hospitalar ao parto. Esc Anna Nery. 2013; 17 (1): 38-45.

20. Martins EF, Lana FCF, Maria E. Tendência da mortalidade perinatal em Belo Horizonte, 1984 a 2005. Rev Bras Enferm. 2010; 63 (3): 446-51.

Received on November 08, 2017

Final version presented on March 17, 2018

Approved on July 18, 2018
21. Lansky S, Friche AAL, Silva AAM, Campos D, Bittencourt DAS, Carvalho ML. Pesquisa Nascer no Brasil: perfil da mortalidade neonatal e avaliação da assistência à gestante e ao recém-nascido. Cad Saúde Pública. 2014; 30 (Suppl.): S192-S207.

22. Lansky S, França E, César CC, Monteiro Neto LC, Leal MC. Mortes perinatais e avaliação da assistência ao parto em maternidades do Sistema Único de Saúde em Belo Horizonte, Minas Gerais, Brasil, 1999. Cad Saúde Pública. 2006, 22 (1): 117-30.

23. Laurenti R, Siqueira AAF, Jorge MHPM, Gotlieb SLD, Pimentel EC. Mortalidade perinatal em hospitais do estado de São Paulo: aspectos metodológicos e algumas características maternas e do concepto. J Hum Growth Dev. 2013; 13 (3): 261-9. 